\title{
Comparison of geneXpert versus sputum/gastric aspirate smear for AFB for the diagnosis of pulmonary tuberculosis in children
}

\author{
Sandhya. $V^{1}$, Prabhavathi. $\mathbf{R}^{2}$, Govindaraj $\mathbf{M}^{3}$. \\ ${ }^{1}$ Dr. Sandhya V., Assistant Professor, ${ }^{2}$ Dr. Prabhavathi R., Assistant Professor, ${ }^{3}$ Dr. Govindaraj M., Professor and HOD, \\ Department of Paediatrics, Dr. B.R. Ambedkar Medical College and Hospital, Bangalore, Karnataka, India.
}

Corresponding Author: Dr. Prabhavathi, GF 05, \#25, Sneha Sindhu Apartment, Kavalbyra Sandra, Shampura Main Road, Near Ambedkar College, Bangalore. Email: drprabha81@gmail.com

\begin{abstract}
Introduction: This was a hospital based observational study for the comparison of geneXpert versus sputum /Gastric aspirate sample for AFB, for diagnosing pulmonary TB in children. The study was donein need for the useful diagnostic test, which is easy to perform, more sensitive and quicker. Gene Xpert assay is a single tube, cartridge based, real time PCR assay for the detection of tuberculosis. Materials and Methods: We enrolled 50 children for our study. Children attending inpatient or outpatient department were screened using a questionnaire. Suspected children were investigated with Complete Blood count, ESR, Chest Xray and Mantoux test. Sputum (in older children) was collected in a sterile container for AFB, and inspecialized container for geneXpert studies. In smaller children gastric aspirates were collected and sent for analysis and the results were compared. Results: Of the 50 children who were included in the study, 42 $(84 \%)$ were less than 10 years, $8(16 \%)$ were $11-16$ years. $46 \%$ of patients had positive contact history of tuberculosis. History of clinical tuberculosis was present in $58 \%$ of the patients. Gene X pert analysis came positive in $42 \%$ of the patients whereas sputum/gastric aspirate analysis for AFB came positive in $12 \%$ of the patients. In our study, sensitivity, specificity, positive predictive value and negative predictive value of Gene Xpert analysis came as $28.6 \%, 100 \%, 100 \%$ and $65.9 \%$ with $70 \%$ accuracy. Conclusion: Gene Xpert analysis can be effectively used as a quick and accurate diagnostic test for the diagnosis of pulmonary tuberculosis in children, especially in a low resource setting, although the bacteriological culture remains the gold standard.
\end{abstract}

Key words: AFB (acid fast bacillus), geneXpert, Pulmonary tuberculosis (TB), Sputum/ gastric aspirate

\section{Introduction}

Pediatric Tuberculosis has many diagnostic challenges such as- paucibacillary infection, absence of clear signs and symptoms, difficulty in obtaining good and adequate samples from children, difficulty in the interpretation of Mantoux test in younger children [1]. Most often, multiple tests are done to make a definitive diagnosis of TB. Some times children are treated empirically to prove TB infection retrospectively.

Hence there is a need for useful diagnostic test, which is easy toperform, more sensitive andquicker. Early diagnosis results in early initiation of treatment by RNTCP and hence better controlof tuberculosis in children.There are various diagnostic modalities for tuberculosis. Gene Xpert assay is a single tube, cartridge based, real time PCR assay for the detection of

Manuscript received: $10^{\text {th }}$ September 2017

Reviewed: $20^{\text {th }}$ September 2017

Author Corrected: $24^{\text {th }}$ September 2017

Accepted for Publication: $28^{\text {th }}$ September 2017 tuberculosis. The system allows simultaneous detection of both M.tuberculosis and rifampicin resistance. It is exceptionally sensitive for the detection of M.tuberculosis even in smear negative specimens. The result is available in 2 hours. Being cartridge based, the risk of cross contamination is less. It requires no in strumentation other than the GeneXpert system.

In 2010, WHO has endorsed the use of this assay as an initial test in all children with suspected TB, though bacteriological confirmation is the gold standard for the diagnosis. Gene Xpert assay is strongly recommended by WHO as an initial diagnostic test in children suspected of having MDR TB or HIV associated TB [2, $3,4]$. This test detects both live and dead bacteria, hence not useful during follow up, except to detect rifampicin resistance. It can also be used to diagnose extrapulmonary tuberculosis depending on what specimen is sent for analysis. 


\section{Materials and Methods}

Study design- Hospital based Observational Study

Sampling- simple random sampling

Sample size- $\mathbf{5 0}$

Selection of samples: Children with signs and symptoms suggestive of tuberculosis attending paediatric outpatient department, those admitted for tuberculosis workup and children whose parents have been started on treatment forTuberculosis under DOTS programme, were considered for the study. These children were screened using a questionnaire. They were investigated with sputum/ gastric aspirate sample for AFB, CXR, Mantoux test, and Gene Xpertassay.

In older children who can produce sputum, sample was collected in a sterile bottle for AFB and another sample collected in a specialized container provided by the DOTS centre for gene Xpert studies. Small children, who are unable to bring out sputum, were admitted as inpatients and nasogastric tube was inserted the previous night. Early morning gastric aspirates were collected and sent for analysis. AFB analysis was done in our college laboratory. Samples for geneXpert analysis were sent to Bowring Hospital or NIMHANS hospital where the test is done free of cost by the government. Confirmed cases were referred to RNTCP for counseling and initiation of treatment. The results of sputum smear for AFB and geneXpert were compared.
The sensitivity and specificity of geneXpert studies were calculated.

Duration of study: -1 year, June 2016 to June 2017

\section{Inclusion criteria}

- Children presenting to outpatient department with symptoms s/o tuberculosis

- Children and siblings of patients on treatment for TB under DOTS (irrespective of age)

- Fever> 2 weeks AND/OR Cough> 2 weeks,

- Unexplained weight loss of $>5 \%$ body weight as compared to highest weight recorded in last 3 months,

- H/o contact within the last 2 years- type of contact pulmonary/ extra pulmonary,duration of contact- min $15 \mathrm{~min}$

- Severe malnutrition / Failure to thrive

- Persistent pneumonia not responding to antibiotics

- Suspected HIV/ immunodeficiency disorder

\section{Exclusion criteria}

- Children with other causes of fever and cough such as lower respiratory tract infection, asthma etc.

- Children with other causes of weight loss such as faulty eating habits, recurrent infections

\section{Results}

The present study was done to compare geneXpert analysis and sputum /gastric aspirate smear for AFB in order to diagnose pulmonary tuberculosis in children. Children presenting to paediatric unit/ outpatient department, satisfying the inclusion criteria were taken into the study. Total numbers of children included in the study were 50 . Of these, 42 children (84\%) were between 1-10 years, 8 children (16\%) were 11-18 yrs as shown in Table 1.

Table-1: Age distribution of patients studied.

\begin{tabular}{|c|c|c|}
\hline Age in years & No. of patients & \% \\
\hline $1-10$ & 42 & 84.0 \\
\hline $11-20$ & 8 & 16.0 \\
\hline Total & 50 & 100.0 \\
\hline
\end{tabular}

Mean \pm SD: $6.74 \pm 3.45$

$23(46 \%)$ children had contact history of tuberculosis where as $29(58 \%)$ children had history of clinical tuberculosis as shown in Table 2 and Table 3.

Table- 2: Contact History TB distribution of patients studied.

\begin{tabular}{|c|c|c|}
\hline Contact History TB & No. of patients & \% \\
\hline No & 27 & 54.0 \\
\hline Yes & 23 & 46.0 \\
\hline Total & $\mathbf{5 0}$ & $\mathbf{1 0 0 . 0}$ \\
\hline
\end{tabular}


Table-3: History of Clinical TB distribution of patients studied.

\begin{tabular}{|c|c|c|}
\hline History Clinical TB & No. of patients & \% \\
\hline No & 21 & 42.0 \\
\hline Yes & 29 & 58.0 \\
\hline
\end{tabular}

Basic investigations for the diagnosis of TB such as Complete Blood Count, ESR, Chest Xray, Mantoux test were done for all the 50 children. Sputum/ gastric aspirate was collected and was sent for geneXpert as well as smear for AFB. The results were compared.

For 21 children (42\%) gene Xpert analysis came positive whereas for 29 children (58\%) gene Xpert was negative as shown in Table 4

Table-4: Gene Xpert Positive distribution of patients studied.

\begin{tabular}{|c|c|c|}
\hline GeneXpert Positive & No. of patients & \% \\
\hline No & 29 & 58.0 \\
\hline Yes & 21 & 42.0 \\
\hline Total & $\mathbf{5 0}$ & $\mathbf{1 0 0 . 0}$ \\
\hline
\end{tabular}

Table 5 shows the sputum positive distribution of patients studied. 6 out of 50 children $(12 \%)$ had sputum smear positive for AFB, remaining 44 children (88\%) had sputum smear negative for AFB

Table-5: Sputum Positive distribution of patients studied.

\begin{tabular}{|c|c|c|}
\hline Sputum Positive & No. of patients & \% \\
\hline No & 44 & 88.0 \\
\hline Yes & 6 & 12.0 \\
\hline Total & $\mathbf{5 0}$ & $\mathbf{1 0 0 . 0}$ \\
\hline
\end{tabular}

Table 6 illustrates the distribution of patients with contact and clinical history of TB having gene Xpert and sputum positivity. Among 50 patients, 21 had Positive gene Xpert analysis of which 14 children (66.7\%) had contact history of TB with a $\mathrm{p}$ value of 0.013 . 18( $85.7 \%$ ) children had clinical history of TB.

This was statistically significant with a $\mathrm{p}$ value of $0.001 .6(28.6 \%)$ children had positive sputum smear for AFB with significant $\mathrm{p}$ value of 0.003 .

Therefore children with contact history and/or clinical history of tuberculosis are more likely to have tuberculosis. Sputum may or may not be positive in all of them,

Table-6: Contact history of TB, History of clinical TB and sputum positivity in relation to Gene Xpert Positive patients.

\begin{tabular}{|c|c|c|c|c|}
\hline \multirow{2}{*}{} & \multicolumn{2}{|c|}{ GeneXpert Positive } & \multirow{2}{*}{$\begin{array}{c}\text { Total } \\
(\mathbf{n = 5 0 )}\end{array}$} & \multirow{2}{*}{ P value } \\
\cline { 2 - 3 } & $\begin{array}{c}\text { No } \\
(\mathbf{n = 2 9 )}\end{array}$ & $\begin{array}{c}\text { Yes } \\
(\mathbf{n}=\mathbf{2 1})\end{array}$ & $23(46 \%)$ & $0.013 *$ \\
\hline Contact History TB & $9(31 \%)$ & $14(66.7 \%)$ & $29(58 \%)$ & $0.001 * *$ \\
\hline History clinical TB & $11(37.9 \%)$ & $18(85.7 \%)$ & $6(12 \%)$ & $0.003 * *$ \\
\hline Sputum Positive & $0(0 \%)$ & $6(28.6 \%)$ & 6 \\
\hline
\end{tabular}

Table 7 explains sensitivity, specificity, PPV, NPV and accuracy of gene Xpert analysis. In our study sensitivity of Gene Xpert analysis was $28 \%$, specificity was $100 \%$, PPV was $100 \%$, NPV was $65.9 \%$, accuracy was $70 \%$. 
Table-7: Sputum Positivity in relation to Gene Xpert Positive results.

\begin{tabular}{|c|c|c|c|}
\hline \multirow{2}{*}{ Sputum Positive } & \multicolumn{2}{|c|}{ Gene Xpert Positive } & \multirow{2}{*}{ Total } \\
\cline { 2 - 4 } & No & Yes & $44(88 \%)$ \\
\hline No & $29(100 \%)$ & $15(71.4 \%)$ & $9(18 \%)$ \\
\hline Yes & $0(0 \%)$ & $6(28.6 \%)$ & $50(100 \%)$ \\
\hline Total & $29(100 \%)$ & $21(100 \%)$ & \\
\hline Sensitivity $\%$ & & $28.6 \%$ & $100.0 \%$ \\
\hline Specificity $\%$ & & $100.0 \%$ & \\
\hline PPV $\%$ & & $65.91 \%$ & \\
\hline NPV $\%$ & & $70.00 \%$ & \\
\hline Accuracy $\%$ & &
\end{tabular}

$\mathrm{P}=0.003^{* *}$, Significant, Chi-Square Test

\section{Discussion}

The diagnosis and timely treatment of pulmonary tuberculosis in children is affected worldwide by the absence of quick and reliable tests. The gene Xpert analysis serves as useful rapid alternative test for the diagnosis of childhood TB [1].

Gene Xpert Assay is a single tube, cartridge based real time PCR assay for the detection of tuberculosis. It is exceptionally sensitive for the detection of mycobacterium TB even in smear negative specimen and the results are available in 2 hrs.

In our study of 50 patients, 42(84\%) were between $1-$ 10 years of age, similar to the study done by Pang. Yet al [1] where percentage of children between 1- 5 years of age enrolled for the study was significantly higher compared to the older age group. They concluded that younger children from low socioeconomic group have a higher risk for tuberculosis. Kumar et al observed similar results in his study [5]. $90.6 \%$ of the patients were $<10$ years of age. On the contrary, study done by Nhu et al [6], almost half of the children (47.9\%) were between 11-16 years old. Only $31.5 \%$ of the children were $0-5$ years of age.

Kumar A et al [5] found that contact history of tuberculosis was present only in $18.4 \%$ of cases and majority of the patients $(81.6 \%)$ had no history of contact with tuberculosis patients. In our study, $46 \%$ of the patients had contact history of tuberculosis and $54 \%$ had no history of contact.

Our study also showed that contact history was positive in 23 children and $66 \%$ of them had Gene Xpert positive.
We can infer that patients end up contacting the disease, even without any history of contact with tuberculosis positive patient. It is also true that if contact history is positive, the chances of getting tuberculosis are higher.

In the study done by Rachow A et al, 164 children were studied. Gene Xpert analysis detected $100 \%$ of smear positive cases. Blood culture was also done and was compared with gene Xpert analysis. Gene Xpert analysis detected 3 fold more confirmed TB cases than smear microscopy. In a similar study done by Sekadde MP et al [9], 9\% of smear positive, culture positive cases were identified by Gene Xpert analysis. The Gene $\mathrm{X}$ pert analysis identified twice as many cases as smear microscopy (79.4\% Vs 41.2\%). Our study showed similar results. Gene Xpert analysis detected more than 2 fold TB cases as compared to smear microcopy (71.4\% Vs $28.65 \%)$ but sputum culture was not considered in our study.

Numbers of studies have demonstrated the utility of gene Xpert analysis in diagnosing pulmonary tuberculosis. In our study, the overall sensitivity, specificity, PPV, NPV of gene Xpert was $28.6 \%, 100 \%$, $100 \%$ and $65.9 \%$ respectively. This is comparable with other studies.

In the study done by Pang $\mathrm{Y}$ et a [1], sensitivity was $48.6 \%$, specificity was $98.6 \%$ Nhuet al 6 compared the sensitivity of Sputum analysis Vs Gene Xpert analysis$37.9 \%$ vs $50 \%$. They also did gene Xpert on 3 sputum samples. Testing the second sample detected 2 additional cases $8.3 \%$ ). Sensitivity did not increase with a third sputum sample. However in our study only one sputum sample was analyzed. Testing the 2nd sample might have increased the sensitivity further. 


\section{Original Research Article}

Boehme CC, Nicol MP et a19 conducted a similar study on 452 children. $6 \%$ had positive smear, $16 \%$ had positive culture and $13 \%$ had positive gene $\mathrm{X}$ pert analysis. 2 samples were tested for gene Xpert. Overall specificity was $98.8 \%$ Sekadde MP et al [8] showed sensitivity of $79 \%$ and specificity of $96.5 \%$ in their study.

Rachow A et al [7] in their study showed sensitivity of $54.7 \%$ compared to culture methods. They tested 2nd and 3rd sample which increased sensitivity by $20 \%$ and additional $16 \%$ respectively. Specificity of gene Xpert was $100 \%$.

Study done by Kumar A et al [5], showed sensitivity$100 \%$, specificity $90.6 \%$, PPV- $71.4 \%$, NPV $100 \%$ of gene Xpert compared to sputum smear samples.

Monika Agarwal et al [10] did a study analyzing both sputum and BAL samples for Gene Xpert and smear for AFB. The study showed overall sensitivity, specificity, PPV and NPV of GeneXpert - 86.8\%, 93.1\%, 78.5\% and $96 \%$ respectively and for BAL sample, $81.4 \%$, $93.4 \%, 73.3 \%$ and $95.7 \%$ respectively.

The overall sensitivity and specificity of AFB smear microscopy were $22.2 \%, \%$ and $78.5 \%$ respectively and for BAL sample $22.2 \%$ and $100 \%$ respectively.

\section{Conclusion}

Gene Xpert analysis can be effectively used as a quick and an accurate diagnostic test for the diagnosis of pulmonary tuberculosis in children, especially in a low resource setting.

Tuberculosis is more prevalent in younger age group. It has to be suspected and evaluated, in spite of contact history being negative.

In our study gene Xpert analysis detected more than 2 fold cases when compared to smear microscopy. This molecular diagnostic assay appears very promising in the diagnosis of childhood tuberculosis. Early diagnosis results in early initiation of treatment by RNTCP and hence better outcome of pulmonary tuberculosis in children.

What this study adds to the existing knowledge- This study reinforces the fact that gene Xpert analysis of sputum or gastric aspirate can be used as a quick and a reliable test in the diagnosis of pulmonary tuberculosis in children especially considering the difficult diagnostic modalities.
Limitation of the study-Our study had few limitations. Firstly sample size was small. Hence larger study with more number of children is required. Gene Xpert analysis was not compared with the gold standard blood/ sputum culture. Rifampicin resistance was not detected as it was included in the objective of the study.

Funding: Nil, Conflict of interest: None initiated, Perission from IRB: Yes

\section{References}

1. Pang Y, Wang Y, Zhao S, Liu J, Zhao Y, Li H. Evaluation of the Xpert MTB/RIF assay in gastriclavage aspirates for diagnosis of smear-negative childhood pulmonary tuberculosis. Pediatr Infect Dis J. 2014; 33: 1047-51. DOI 10. 1097/INF.000000000000 0403.

2.World Health Organization. Automated real-time nucleic acid amplification technology for rapid and simultaneous detection of tuberculosis and rifampicin resistance: Xpert MTB/RI assay for the diagnosis of pulmonary and extra-pulmonary $\mathrm{TB}$ in adults and children. Policy update. available from http://apps.who. int/iris/bitstream/10665/112472/1/9789241506335_eng. pdf. Accessed November 5,2014

3. World Health Organization. Guidance for national tuberculosis programs on the management of tuberculosis in children. Second edition Availablfrom: http://apps.who.int/medicinedocs/documents/s21535en/ s21535en.pdf.

4. Government of India. Central TB Division Directorate General of Health Services, Ministry of Health and Family Welfare. TB India 2014 Revised National TB Control Programme. Annual Status Rep: www.tbcindia.nic.in/pdfs/TB\%20INDIA\%202014.pdf.

5. Kumar A, Das S, Paul DK. A Study on the Role of Cartridge Based Nucleic Acid Amplification Test (CBNAAT) for DiagnosingPediatric Tuberculosis in a Tertiary Care Hospital in Eastern India. Acad J Ped Neonatol. 2018; 6(3): 555745. DOI: 10.19080/AJPN. 2018.06.555745.

6. Nhu NT, Ha DT, Anh ND, et al. Evaluation of Xpert MTB/RIF and MODS assay for the diagnosis of pediatric tuberculosis. BMC Infect Dis. 2013 Jan 23;13: 31. doi: 10.1186/1471-2334-13-31.

7. Rachow A, Clowes P, Saathoff E, Mtafya B, Michael E, NtinginyaEn, Kowour D, Rojas-Ponce G, Kroidl A, Maboko L, et al: Incresed and expedited case detection 
by xpert MTB/RIF assay in childhood tuberculosis: a prospective cohort study. Clin Infect Dis. 2012, 54 (10): 1388-1396.DOI: 10.1093?cid/cis 190. Epub 2012 Apr 3

8. Sekadde MP, Wobudeya E, Joloba ML, et al. Evaluation of the Xpert MTB/RIF test for the diagnosis of childhood pulmonary tuberculosis in Uganda: a cross-sectional diagnostic study. BMC Infect Dis. 2013 Mar 12;13:133. doi: 10.1186/1471-2334-13-133.

9. Boehme CC, Nicol MP, NabetaP, Michael JS, Gotuzzo E, Tahirli R, Gler MT, Blackemore R, Worodria W, Gray $\mathrm{C}$ et al: Feasibility, diagnostic accuracy, and effectiveness of decentralized use of the Xpert MTB/RIF test for diagnosis of tuberculosis and multidrug resistance; a multicenter implementation study. Lancet. 2011, 377 (9776): 1495-1505. Doi: 10. 1016 / S0140-6736(11)60438-8

10. Monika Agarwal, Ashish Bajaj, Vinay Bhatia et al. Comparative study of Gene Xpert with $\mathrm{Zn}$ stain and Culture in samples of suspected Pulmonary Tuberculosis. J Clin Diagn Res. 2016 May; 10(5): DC09DC12. Doi: 10.7860/JCDR/ 2016/ 18837.7755

11. GandraNR, Jayasri Helen Gali. GeneXpert: a game changer in the detection and diagnosis of childhood tuberculosis. Int J Contemp Pediatr. 2018 Jan; 5 (1): 3541. DOI: http: //dx.doi.org/10. 18203/ 2349-3291. ijcp 20175087

\section{How to cite this article?}

Sandhya. V, Prabhavathi. R, Govindaraj M. Comparison of geneXpert versus sputum/gastric aspirate smear for AFB for the diagnosis of pulmonary tuberculosis in children. Int J Pediatr Res. 2018;5(10):521-526. doi:10.17511/ijpr.2018.i10.07. 